Kragujevac Journal of Mathematics

Volume 40(2) (2016), Pages 290-297.

\title{
PRODUCT CORDIAL LABELING OF LINE GRAPH OF SOME GRAPHS
}

\author{
S. K. VAIDYA ${ }^{1}$ AND C. M. BARASARA ${ }^{2}$
}

\begin{abstract}
The line graph $L(G)$ of a graph $G$ is the graph whose vertex set is $E(G)$ and two vertices are adjacent in $L(G)$ whenever they are incident in $G$. In this paper we have investigated product cordial labeling of line graph of some product cordial graphs.
\end{abstract}

\section{INTRODUCTION}

The graph labeling is one of the concepts in graph theory which has attracted many researchers to work on it because of its diversified and rigorous application in fields such as design and analysis of communication networks, military surveillance, social sciences, optimization and linear algebra. Many types of graph labelings are available in the existing literature. A brief account of comprehensive bibliography of papers on the concept of graph labeling is available in a dynamic survey of graph labeling by Gallian [2].

We begin with finite, undirected and connected graph $G=(V(G), E(G))$ without loops and multiple edges. For the various graph theoretic notations and terminology, we follow West [9].

Definition 1.1. A graph labeling is an assignment of integers to the vertices or edges or both subject to certain condition(s). If the domain of mapping is the set of vertices (edges) then the labeling is called a vertex (an edge) labeling.

In 1987, Cahit [1] has introduced the concept of cordial labeling which is defined as follows.

Key words and phrases. Cordial labeling, product cordial labeling, line graph.

2010 Mathematics Subject Classification. Primary: 05C78. Secondary: 05C76, 05C38.

Received: December 15, 2014.

Accepted: August 7, 2016. 
Definition 1.2. For a graph $G=(V(G), E(G))$, a vertex labeling function $f: V(G) \rightarrow\{0,1\}$ induces an edge labeling function $f^{*}: E(G) \rightarrow\{0,1\}$ defined as $f^{*}(e=u v)=|f(u)-f(v)|$. Then $f$ is called a cordial labeling of graph $G$ if $\left|v_{f}(0)-v_{f}(1)\right| \leq 1$ and $\left|e_{f}(0)-e_{f}(1)\right| \leq 1$ where $v_{f}(i)$ is the number of vertices of $G$ having label $i$ under $f$ and $e_{f}(i)$ is the number of edges of $G$ having label $i$ under $f^{*}$ for $i=1,2$. A graph $G$ is called cordial graph if it admits a cordial labeling.

Some labeling schemes are also introduced with minor variations in cordial theme. Some of them are A-Cordial labeling, H-Cordial labeling, Prime cordial labeling, Product cordial labeling, Edge product cordial labeling, etc.

Definition 1.3. For a graph $G=(V(G), E(G))$, a vertex labeling function $f: V(G) \rightarrow\{0,1\}$ induces an edge labeling function $f^{*}: E(G) \rightarrow\{0,1\}$ defined as $f^{*}(e=u v)=f(u) f(v)$. Then $f$ is called a product cordial labeling of graph $G$ if $\left|v_{f}(0)-v_{f}(1)\right| \leq 1$ and $\left|e_{f}(0)-e_{f}(1)\right| \leq 1$. A graph $G$ is called product cordial graph if it admits a product cordial labeling.

In 2004, Sundaram et al. [3] have introduced the concept of product cordial labeling. In the same paper they have investigated product cordial labeling for some standard graphs.

Vaidya and Barasara [4-8] have also investigated many results on product cordial labeling.

Definition 1.4. The line graph $L(G)$ of a graph $G$ is the graph whose vertices are the edges of $G$, with ef $\in E(L(G))$ when $e=u v$ and $f=v w$ in $G$.

In this paper we have investigated product cordial labeling of line graph of some product cordial graphs.

\section{Main Results}

Definition 2.1. The middle graph $M(G)$ of a graph $G$ is the graph whose vertex set is $V(G) \cup E(G)$ and in which two vertices are adjacent if and only if either they are adjacent edges of $G$ or one is a vertex of $G$ and the other is an edge incident with it.

Theorem 2.1. The graph $L\left(M\left(P_{n}\right)\right)$ is product cordial for odd $n$ and not product cordial for even $n$.

Proof. Let $e_{1}, e_{2}, \ldots, e_{n-2}$ be the edges of path $P_{n-1}$ in $M\left(P_{n}\right)$ and $e_{1}^{\prime}, e_{2}^{\prime}, \ldots, e_{2 n-2}^{\prime}$ are the added edges for the construction of $M\left(P_{n}\right)$. Then $V\left(L\left(M\left(P_{n}\right)\right)\right)=\left\{e_{1}, e_{2}, \ldots\right.$, $\left.e_{n-2}, e_{1}^{\prime}, e_{2}^{\prime}, \ldots, e_{2 n-2}^{\prime}\right\}$. Hence $\left|V\left(L\left(M\left(P_{n}\right)\right)\right)\right|=3 n-4$ and $\left|E\left(L\left(M\left(P_{n}\right)\right)\right)\right|=7 n-14$.

To define $f: V\left(L\left(M\left(P_{n}\right)\right)\right) \rightarrow\{0,1\}$, we consider following two cases. 
Case 1: When $n$ is odd.

$$
\begin{aligned}
& f\left(e_{i}\right)=1, \quad 1 \leq i \leq \frac{n-1}{2} \\
& f\left(e_{i}\right)=0, \quad \frac{n+1}{2} \leq i \leq n-2, \\
& f\left(e_{i}^{\prime}\right)=1, \quad 3 \leq i \leq n+1 \\
& f\left(e_{i}^{\prime}\right)=0, \quad n+2 \leq i \leq 2(n-1) \text { and } i=1,2 .
\end{aligned}
$$

In view of above labeling pattern we have

$$
\begin{aligned}
v_{f}(1) & =v_{f}(0)+1=\frac{3 n-3}{2}, \\
e_{f}(1)+1 & =e_{f}(0)=\frac{7 n-13}{2} .
\end{aligned}
$$

Thus we have $\left|v_{f}(1)-v_{f}(0)\right| \leq 1$ and $\left|e_{f}(1)-e_{f}(0)\right| \leq 1$.

Case 2: When $n$ is even.

In order to satisfy the vertex condition for product cordial graph it is essential to assign label 0 to $\frac{3 n-4}{2}$ vertices out of $3 n-4$ vertices. The vertices with label 0 will give rise at least $\frac{7 n-12}{2}$ edges with label 0 and at most $\frac{7 n-16}{2}$ edges with label 1 out of total $7 n-14$ edges. Therefore $\left|e_{f}(1)-e_{f}(0)\right| \geq 2$. Consequently the graph is not product cordial.

Hence, the graph $L\left(M\left(P_{n}\right)\right)$ is product cordial for odd $n$ and not product cordial for even $n$.

Example 2.1. The line graph of $M\left(P_{5}\right)$ and its product cordial labeling is shown in Figure 1.

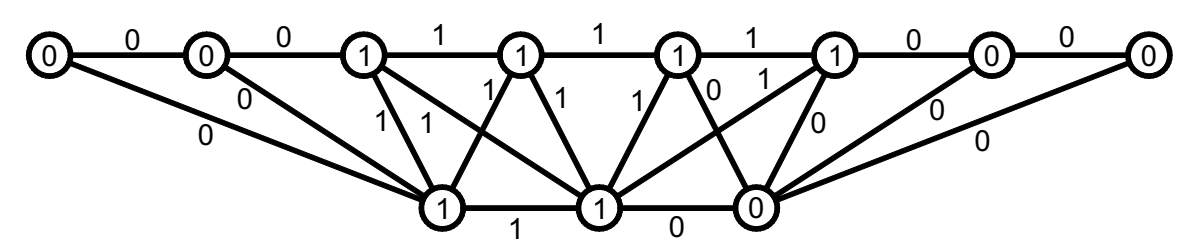

Figure 1. $L\left(M\left(P_{5}\right)\right)$ and its product cordial labeling.

Definition 2.2. The triangular snake $T_{n}$ is obtained from the path $P_{n}$ by replacing every edge of a path by a triangle $C_{3}$.

Theorem 2.2. The graph $L\left(T_{n}\right)$ is product cordial for even $n$ and not product cordial for odd $n$.

Proof. Let $e_{1}, e_{2}, \ldots, e_{n-1}$ be the edges of $T_{n}$ corresponding to path $P_{n}$ and $e_{1}^{\prime}, e_{2}^{\prime}, \ldots$, $e_{2 n-2}^{\prime}$ are the added edges to path $P_{n}$ for the construction of $T_{n}$. Then $V\left(L\left(T_{n}\right)\right)=$ 
$\left\{e_{1}, e_{2}, \ldots, e_{n-1}, e_{1}^{\prime}, e_{2}^{\prime}, \ldots, e_{2 n-2}^{\prime}\right\}$. Hence $\left|V\left(L\left(T_{n}\right)\right)\right|=3 n-3$ and $\left|E\left(L\left(T_{n}\right)\right)\right|=$ $7 n-11$.

To define $f: V\left(L\left(T_{n}\right)\right) \rightarrow\{0,1\}$, we consider following two cases.

Case 1: When $n$ is even.

$$
\begin{aligned}
& f\left(e_{i}\right)=1, \quad 1 \leq i \leq \frac{n}{2}, \\
& f\left(e_{i}\right)=0, \quad \frac{n}{2}+1 \leq i \leq n-1, \\
& f\left(e_{1}^{\prime}\right)=0, \\
& f\left(e_{i}^{\prime}\right)=1, \quad 2 \leq i \leq n, \\
& f\left(e_{i}^{\prime}\right)=0, \quad n+1 \leq i \leq 2(n-1) .
\end{aligned}
$$

In view of above labeling pattern we have

$$
\begin{aligned}
v_{f}(1) & =v_{f}(0)+1=\frac{3 n-2}{2}, \\
e_{f}(1)+1 & =e_{f}(0)=\frac{7 n-10}{2} .
\end{aligned}
$$

Thus we have $\left|v_{f}(1)-v_{f}(0)\right| \leq 1$ and $\left|e_{f}(1)-e_{f}(0)\right| \leq 1$.

Case 2: When $n$ is odd.

In order to satisfy the vertex condition for product cordial graph it is essential to assign label 0 to $\frac{3 n-3}{2}$ vertices out of $3 n-3$ vertices. The vertices with label 0 will give rise at least $\frac{7 n-7}{2}$ edges with label 0 and at most $\frac{7 n-15}{2}$ edges with label 1 out of total $7 n-11$ edges. Therefore $\left|e_{f}(1)-e_{f}(0)\right| \geq 4$. Consequently the graph is not product cordial.

Hence, the graph $L\left(T_{n}\right)$ is product cordial for even $n$ and not product cordial for odd $n$.

Example 2.2. The graph $L\left(T_{4}\right)$ and its product cordial labeling is shown in Figure 2.

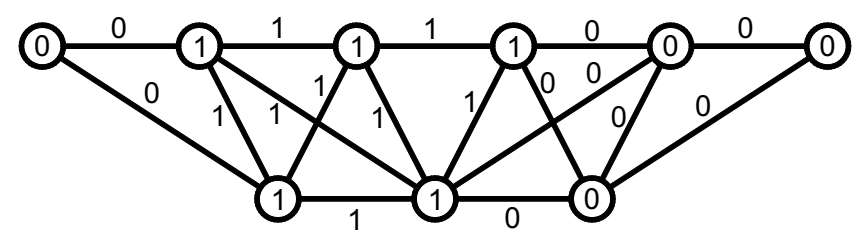

FiguRE 2. $L\left(T_{4}\right)$ and its product cordial labeling.

Definition 2.3. The armed crown $A C r_{n}$ is a graph in which path $P_{2}$ is attached at each vertex of cycle $C_{n}$ by an edge.

Theorem 2.3. The graph $L\left(A C r_{n}\right)$ is a product cordial graph.

Proof. For graph $A C r_{n}$, let $e_{1}, e_{2}, \ldots, e_{n}$ be he edges of $C_{n}$ and $e_{1}^{\prime}, e_{2}^{\prime}, \ldots, e_{n}^{\prime}$ be the edges corresponding to paths and $e_{1}^{\prime \prime}, e_{2}^{\prime \prime}, \ldots, e_{n}^{\prime \prime}$ be the edges joining path and cycle. Then $V\left(L\left(A C r_{n}\right)\right)=\left\{e_{1}, e_{2}, \ldots, e_{n}, e_{1}^{\prime}, e_{2}^{\prime}, \ldots, e_{n}^{\prime}, e_{1}^{\prime \prime}, e_{2}^{\prime \prime}, \ldots, e_{n}^{\prime \prime}\right\}$. 
Hence $\left|V\left(L\left(A C r_{n}\right)\right)\right|=3 n$ and $\left|E\left(L\left(A C r_{n}\right)\right)\right|=4 n$.

To define $f: V\left(L\left(A C r_{n}\right)\right) \rightarrow\{0,1\}$ we consider following two cases.

Case 1: When $n$ is odd.

$$
\begin{aligned}
& f\left(e_{i}\right)=1, \quad 1 \leq i \leq n, \\
& f\left(e_{1}^{\prime}\right)=1, \\
& f\left(e_{i}^{\prime}\right)=0, \quad 2 \leq i \leq n \\
& f\left(e_{i}^{\prime \prime}\right)=1, \quad 1 \leq i \leq \frac{n-1}{2} \\
& f\left(e_{i}^{\prime \prime}\right)=0, \quad \frac{n+1}{2} \leq i \leq n .
\end{aligned}
$$

In view of above labeling pattern we have

$$
\begin{aligned}
& v_{f}(1)=v_{f}(0)+1=\frac{3 n+1}{2}, \\
& e_{f}(1)=e_{f}(0)=2 n .
\end{aligned}
$$

Case 2: When $n$ is even.

$$
\begin{aligned}
f\left(e_{i}\right)=1, & 1 \leq i \leq n \\
f\left(e_{i}^{\prime}\right)=0, & 1 \leq i \leq n \\
f\left(e_{i}^{\prime \prime}\right)=1, & 1 \leq i \leq \frac{n}{2} \\
f\left(e_{i}^{\prime \prime}\right)=0, & \frac{n}{2}+1 \leq i \leq n .
\end{aligned}
$$

In view of above labeling pattern we have

$$
\begin{aligned}
& v_{f}(1)=v_{f}(0)=\frac{3 n}{2}, \\
& e_{f}(1)=e_{f}(0)=2 n .
\end{aligned}
$$

Thus in both the case we have $\left|v_{f}(1)-v_{f}(0)\right| \leq 1$ and $\left|e_{f}(1)-e_{f}(0)\right| \leq 1$. Hence, the graph $L\left(A C r_{n}\right)$ is a product cordial graph.

Example 2.3. The line graph of $A C r_{5}$ and its product cordial labeling is shown in Figure 3.

Definition 2.4. The square of graph $G$ is denoted by $G^{2}$ and defined as the graph with distance 1 or 2 apart in $G$.

Theorem 2.4. The graph $L\left(P_{n}^{2}\right)$ is not product cordial for odd $n>3$.

Proof. For the graph $L\left(P_{n}^{2}\right)$ for odd $n>3,\left|V\left(L\left(P_{n}^{2}\right)\right)\right|=2 n-3$ and $\left|E\left(L\left(P_{n}^{2}\right)\right)\right|=$ $6 n-16$. In order to satisfy the vertex condition for product cordial graph it is essential to assign label 0 to $\left\lfloor\frac{2 n-3}{2}\right\rfloor$ vertices out of $2 n-3$ vertices. The vertices with label 0 will give rise at least $\frac{7 n-19}{2}$ edges with label 0 and at most $\frac{5 n-13}{2}$ edges with label 1 


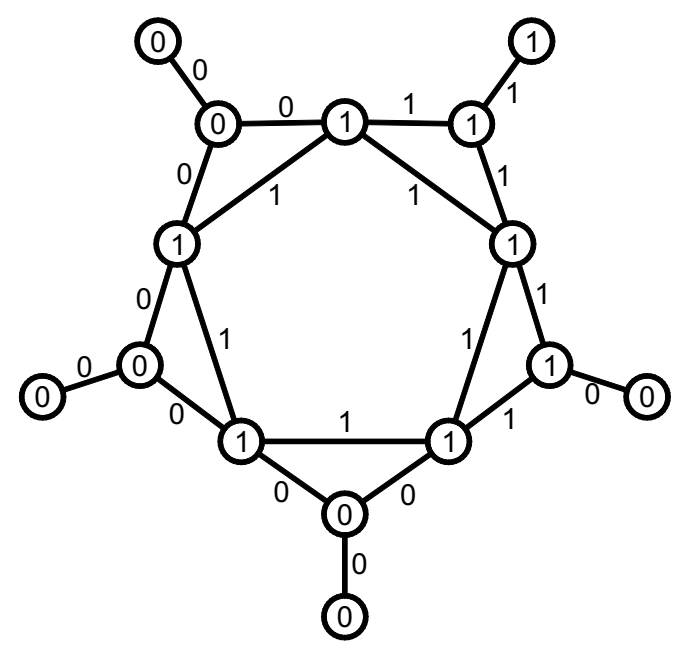

Figure 3. $L\left(A C r_{5}\right)$ and its product cordial labeling.

out of total $6 n-16$ edges. Therefore $\left|e_{f}(1)-e_{f}(0)\right| \geq n-3>1$. Consequently the graph is not product cordial.

Hence, the graph $L\left(P_{n}^{2}\right)$ is not product cordial for odd $n>3$.

Remark 2.1. The graph $P_{3}^{2}$ is same as $C_{3}$ and hence $L\left(P_{3}^{2}\right)=C_{3}$, which is product cordial as proved in [3].

Definition 2.5. The splitting graph $S^{\prime}(G)$ of a graph $G$ is obtained by adding to each vertex $v$ a new vertex $v^{\prime}$ such that $v^{\prime}$ is adjacent to every vertex that is adjacent to $v$ in $G$.

Theorem 2.5. The graph $L\left(S^{\prime}\left(P_{n}\right)\right)$ is not product cordial for even $n>2$.

Proof. For the graph $L\left(S^{\prime}\left(P_{n}\right)\right)$ for even $n>2,\left|V\left(L\left(S^{\prime}\left(P_{n}\right)\right)\right)\right|=3 n-3$ and $\left|E\left(L\left(S^{\prime}\left(P_{n}\right)\right)\right)\right|=7 n-12$. In order to satisfy the vertex condition for product cordial graph it is essential to assign label 0 to $\left\lfloor\frac{3 n-3}{2}\right\rfloor$ vertices out of $3 n-3$ vertices. The vertices with label 0 will give rise at least $\frac{7 n-10}{2}$ edges with label 0 and at most $\frac{7 n-14}{2}$ edges with label 1 out of total $7 n-12$ edges. Therefore $\left|e_{f}(1)-e_{f}(0)\right| \geq 2$. Consequently the graph is not product cordial.

Hence, the graph $L\left(S^{\prime}\left(P_{n}\right)\right)$ is not product cordial for even $n>2$.

Remark 2.2. The graph $S^{\prime}\left(P_{2}\right)$ is same as $P_{4}$ and hence $L\left(S^{\prime}\left(P_{2}\right)\right)=P_{3}$, which is product cordial as proved in [3].

Definition 2.6. The total graph $T(G)$ of a graph $G$ is the graph whose vertex set is $V(G) \cup E(G)$ and two vertices are adjacent in $T(G)$ whenever they are either adjacent or incident in $G$.

Theorem 2.6. The graph $L\left(T\left(P_{n}\right)\right)$ is not product cordial graph. 
Proof. For the graph $L\left(T\left(P_{n}\right)\right),\left|V\left(L\left(T\left(P_{n}\right)\right)\right)\right|=4 n-5$ and $\left|E\left(L\left(T\left(P_{n}\right)\right)\right)\right|=12 n-22$. We will consider following two cases.

Case 1: When $n$ is odd. In order to satisfy the vertex condition for product cordial graph it is essential to assign label 0 to $\frac{4 n-5}{2}$ vertices out of $4 n-5$ vertices. The vertices with label 0 will give rise at least $7 n-13$ edges with label 0 and at most $5 n-9$ edges with label 1 out of total $12-22$ edges. Therefore $\left|e_{f}(1)-e_{f}(0)\right| \geq 2 n-4>1$. Consequently the graph is not product cordial.

Case 2: When $n$ is even.

In order to satisfy the vertex condition for product cordial graph it is essential to assign label 0 to $\left\lfloor\frac{4 n-5}{2}\right\rfloor$ vertices out of $4 n-5$ vertices. The vertices with label 0 will give rise at least $7 n-12$ edges with label 0 and at most $5 n-10$ edges with label 1 out of total 12-22 edges. Therefore $\left|e_{f}(1)-e_{f}(0)\right| \geq 2 n-2>1$. Consequently the graph is not product cordial.

Hence, the graph $L\left(T\left(P_{n}\right)\right)$ is not product cordial graph.

\section{Concluding Remarks}

The graphs $T_{n}, P_{n}^{2}$ and $T\left(P_{n}\right)$ are proved to be product cordial graphs by Sundaram et al. [3] and $M\left(P_{n}\right), A C_{n}$ and $S^{\prime}\left(P_{n}\right)$ are proved to be product cordial graphs by Vaidya and Barasara $[4,7,8]$ while here we prove that the line graph of $M\left(P_{n}\right), A C_{n}$ and $T_{n}$ are product cordial graphs and the line graph of $S^{\prime}\left(P_{n}\right), P_{n}^{2}$ and $T\left(P_{n}\right)$ are not product cordial graphs. Thus line graphs are not invariant for product cordial labeling in general.

\section{REFERENCES}

[1] I. Cahit, Cordial graphs: A weaker version of graceful and harmonious graphs, Ars Combin. 23 (1987), 201-207.

[2] J. A. Gallian, A dynamic survey of graph labeling, Electron. J. Combin. 16 (2013), Article ID: DS6.

[3] M. Sundaram, R. Ponraj and S. Somasundaram, Product cordial labeling of graphs, Bull. Pure Appl. Sci. Sect. E Math. Stat. 23 (2004), 155-163.

[4] S. K. Vaidya and C. M. Barasara, Product cordial graphs in the context of some graph operations, International Journal of Mathematics and Scientific Computing 1(2) (2011), 1-6.

[5] S. K. Vaidya and C. M. Barasara, Product cordial labeling for some new graphs, Journal of Mathematics Research 3(2) (2011), 206-211.

[6] S. K. Vaidya and C. M. Barasara, Some product cordial graphs, Elixir Discrete Mathematics 41 (2011), 5948-5952.

[7] S. K. Vaidya and C. M. Barasara, Further results on product cordial graphs, International Journal of Mathematics and Soft Computing 2(2) (2012), 67-74.

[8] S. K. Vaidya and C. M. Barasara, Further results on product cordial labeling, International Journal of Mathematical Combinatorics 3 (2012), 64-71.

[9] D. B. West, Introduction to Graph Theory, 2nd Edition, Prentice-Hall, New Delhi, 2001. 
${ }^{1}$ Department of Mathematics, SAURASHTRA UNIVERSITY, RAJKot, Gujarat - 360005, India.

E-mail address: samirkvaidya@yahoo.co.in

${ }^{2}$ Atmiya Institute of Technology and Science, RAJKOT, GuJARAT - 360005, InDiA.

E-mail address: chirag.barasara@gmail.com 